\title{
O ENSINO DE MÉTODOS QUALITATIVOS EM PSICOLOGIA: ampliando perspectivas científicas sob o enfoque de Direitos Humanos
}

\author{
Laura Cristina Eiras Coelho Soares \\ Ariane Agnes Corradi \\ Déborah David Pereira ${ }^{1}$ \\ Universidade Federal de Minas Gerais - UFMG
}

\begin{abstract}
Resumo
Este estudo objetiva relatar experiências de ensino-aprendizagem de métodos qualitativos construídas com estudantes, discentes e monitoras de um curso de graduação em Psicologia, tendo como suporte a discussão sobre Direitos Humanos. Tem-se em vista o desafio de ampliar a concepção de ciência, ainda muito associada ao modelo positivista, para incluir a perspectiva de epistemologias emergentes. Esse debate requer a contextualização do conhecimento produzido, especialmente no Brasil de hoje, marcado por um histórico de exclusão social e posturas antagônicas. Com o propósito didático de gerar e fortalecer a consciência dos discentes acerca da diversidade de vozes sociais e da necessidade de se engajar politicamente para promover os Direitos Humanos, a disciplina é estruturada para abarcar o surgimento e os aspectos éticos de métodos qualitativos nas Ciências Humanas e na Psicologia, a relevância da pesquisa para os psicólogos e os principais aspectos de algumas modalidades e técnicas de coleta e análise de dados. Algumas estratégias didáticas consistem na elaboração de um projeto de pesquisa, avaliação de painéis em eventos científicos locais e entrevistas com estagiários em Psicologia. Essa pluralidade de atividades fomenta a formação metodológica dos estudantes, aproximando-os da complexidade e do dinamismo das abordagens qualitativas, bem como refletindo a policromia das epistemologias emergentes.
\end{abstract}

Palavras-chave: ensino; Psicologia; métodos qualitativos; epistemologias emergentes; Direitos Humanos

\begin{abstract}
This study aims to report qualitative methods' teaching-learning experiences built with students, lecturers, and teaching assistants in a psychology undergraduate course, having the Human Rights discussion as support. It takes into consideration the challenge to broaden the conception of science, yet much associated with the positivist model, to include the perspective of emergent epistemologies. This debate requires the contextualization of the knowledge produced, especially in todays' Brazil, marked by a history of social exclusion and antagonist positions. Following the didactic purpose of raising students' awareness on the diversity of societal voices and the need to engage politically to promote Human Rights, the course is structured to cover the emergence and ethics of qualitative methods in human sciences and Psychology, the relevance of research for psychologists, and the main features of some research modalities and techniques of data collection and analysis. Teaching strategies include elaboration of a research proposal, assessment of posters in a scientific local event, and interviews with Psychology interns. This plurality of activities fosters the students' methodological formation, brings the dynamism and complexity of qualitative approaches closer to them, and reflects the polychrome of emergent epistemologies.
\end{abstract}

Keywords: teaching; Psychology; qualitative methods; emergent epistemologies; Human Rights 


\section{Introdução}

O emprego de métodos qualitativos em Psicologia remonta aos primórdios da história dessa ciência, com o uso da introspecção por Wundt e de entrevistas qualitativas por Piaget, Adorno e Freud, para citar alguns exemplos (WILLIG; STAINTON-ROGERS, 2008). Contudo, à medida que a Psicologia busca afirmar seu caráter científico dentro do modelo de ciência moderna do Século XIX, tomando por objeto o comportamento, os métodos qualitativos passam a ser rotulados como não científicos. O fortalecimento da Psicologia como uma ciência orientada pelo paradigma positivista e suas reformulações (MACHAMER, 2002) e pela orientação epistemológica naturalista ${ }^{2}$ (D’AGOSTINO, 2010) como o único caminho legítimo de produção de conhecimento fez com que prevalecesse uma forte associação do saber psicológico à tradição experimental-quantitativa (ROMÃO-DIAS, 2013; GONZÁLEZ-REY, 2011). Além do projeto de ciência moderna, questões socioeconômicas também motivaram o abandono da Psicologia como uma ciência da subjetividade para se tornar uma ciência das respostas comportamentais observáveis pelo experimentador.

Tem-se argumentado (e.g., Jones; Elcock, 2001; Richards, 1996) que essa mudança foi ao menos parcialmente orientada por uma demanda socioeconômica de que a Psicologia se tornasse mais utilitarista - para gerar um conhecimento que pudesse ser útil para gerenciar a sociedade e seus problemas (em áreas como crime, saúde mental e seleção de crianças para escolas e de pessoas para empregos). Uma das consequências disso foi a marginalização e a consequente desvalorização de métodos subjetivistas de pesquisa psicológica. Outra consequência foi uma tendência de fazer julgamentos sobre indivíduos com base em dados agregados. (WILLIG; STAINTON-ROGERS, 2008, p. 4, tradução nossa).

Somente a partir dos anos 1970 as epistemologias emergentes em Psicologia ganharam espaço, inspiradas em disciplinas como a Antropologia e a Sociologia, que desde o início do Século XX questionavam o projeto de ciência moderna positivista. Nesse momento da história, fortaleceu-se o compartilhamento de saberes entre as Ciências Humanas e Sociais dentro da abordagem qualitativa (ROMÃO-DIAS, 2013; GONZÁLEZ-REY, 2011).

Atualmente, portanto, reconhece-se que estudos quantitativos e qualitativos não se enquadram em um único contínuo, possuindo naturezas diferentes por estarem associados a paradigmas científicos diferentes (BURRELL; MORGAN, 1979; MINAYO; SANCHES, 1993). Os métodos quantitativos estão associados a uma perspectiva científica baseada em uma posição ontológica realista, relativa ao modelo positivista de construção do conhecimento, cujo objetivo é encontrar leis universais para explicar diversos fenômenos, inclusive humanos e sociais. Os métodos qualitativos, por sua vez, estão associados a uma perspectiva científica baseada em uma ontologia subjetivista, a qual permite a emergência de novas epistemologias que captem as características contextualizadas e específicas dos fenômenos humanos e sociais. Nesse sentido, os métodos de pesquisa decorrem das escolhas epistemológicas para compreender determinados fenômenos e, principalmente no caso da 
Psicologia, também de uma visão de ser humano (BURRELL; MORGAN, 1979; ROMÃODIAS, 2013). Dado o caráter multiparadigmático da Psicologia (ABIB, 2009), nenhum método, por si só, apresenta-se como mais científico ou mais relevante. Ademais, Minayo e Sanches (1993) apontam que essas duas abordagens metodológicas não se opõem completamente: o encontro se dá uma vez que uma pode levantar questionamentos a serem desenvolvidos pela outra.

Abandonando o objetivo de mensuração, as expectativas de neutralidade do pesquisador, o pressuposto de objetividade e a busca de generalização dos resultados preconizados pelo modelo positivista de ciência, as metodologias qualitativas, apoiadas por paradigmas científicos emergentes, propõem abarcar a complexidade de fenômenos sociais e subjetivos, explorando-os em profundidade e de maneira contextualizada. Assim, as matérias-primas da pesquisa tornam-se a palavra e a vida cotidiana (MINAYO; SANCHES, 1993). Abrem-se, desse modo, outras possibilidades de investigação que priorizam as perspectivas e as vivências dos sujeitos envolvidos, sobretudo daqueles cujas subjetividades têm sido pouco consideradas pela atuação e pela pesquisa psicológica.

Destaca-se, porém, a persistência, entre profissionais e pesquisadores psicólogos adeptos da vertente positivista, da crença na não cientificidade ou em um caráter duvidoso dos caminhos metodológicos qualitativos, negligenciando as contribuições técnicas, teóricas e sociopolíticas que eles permitem (ANTUNES, 2017). Essa crença também é identificada entre alunos no início do curso de Psicologia no Brasil, de modo a apontar a necessidade de construção de planos de ensino que favoreçam a abertura dos graduandos à diversidade do fazer científico.

As Diretrizes Curriculares Nacionais para os cursos de graduação em Psicologia brasileiros indicam a necessidade de dedicar um espaço no currículo para a construção e efetivação desses planos. São eixos estruturantes das propostas de curso, entre outros, os fundamentos epistemológicos e históricos do saber psicológico, os procedimentos para a investigação científica e a prática profissional e, em especial, os fundamentos teóricometodológicos da produção de conhecimento em Psicologia (BRASIL, 2011). Assim, tornase crucial a discussão sobre métodos pedagógicos e escolhas bibliográficas acerca das epistemologias emergentes e das metodologias qualitativas, a fim de potencializar a contribuição dessas temáticas à formação dos estudantes em Psicologia. Nesse sentido, a aplicação de estratégias de ensino-aprendizagem apropriadas à natureza dos métodos qualitativos, por estimular o reconhecimento e a valorização da diversidade epistemológica em Psicologia, pode favorecer consideravelmente a trajetória acadêmica dos discentes e a aprendizagem de diversas abordagens psicológicas (ROMÃO-DIAS, 2013).

Em vista disso, este trabalho objetiva, primeiramente, compartilhar experiências de ensino-aprendizagem que vêm sendo (re)construídas junto a estudantes, monitoras e professoras que assumem a disciplina de Métodos Qualitativos em Psicologia em uma instituição de ensino superior federal. No relato dessas experiências, buscamos fomentar a discussão sobre as estratégias de ensino por meio do detalhamento da estrutura da disciplina: as escolhas de referências para leituras, as temáticas abordadas e os recursos didáticos utilizados. Embora existam muitos materiais sobre abordagens qualitativas produzidos no 
mundo, a literatura sobre o modo de ensinar métodos qualitativos em Psicologia ou em outros campos é recente e ainda limitada (ANTUNES, 2017). Na literatura internacional, encontramos o estudo de Antunes (2017), no contexto de uma pós-graduação em Psicologia da Educação em Portugal, e o número especial da revista Psychology Learning and Teaching, editada por Gibson e Sullivan (2012), cujos artigos descrevem o ensino de diferentes metodologias qualitativas em Psicologia. Não encontramos estudos brasileiros sobre essa temática.

Assim, este estudo busca contribuir para a literatura brasileira sobre ensino de métodos qualitativos, incluindo, além da dimensão instrumental do seu uso, também a relação entre pesquisa qualitativa em Psicologia e Direitos Humanos (DH). Essa reflexão auxiliou a construção do projeto da disciplina e representa mais uma carência identificada na literatura (i.e., BOCK; GIANFALDONI, 2010). Conforme Gibson e Sullivan (2012) destacam, o mero uso de métodos qualitativos não implica em uma Psicologia informada politicamente. A linha divisória está, portanto, entre as abordagens que reforçam o status quo e aquelas que buscam examinar os problemas e os silêncios impostos por esse status quo na pesquisa e na prática psicológicas. Em nosso caso, essa linha divisória está associada à lente de Direitos Humanos como dimensão inerente e primordial à pesquisa qualitativa crítica e contextualizada.

Historicamente, a relação entre métodos qualitativos em Psicologia e Direitos Humanos fica comprometida por desenvolvimentos epistemológicos tortuosos da Psicologia moderna, conforme descrevem Willig e Stainton-Rogers (2008, p. 4):

Questionários permitiram aos cientistas sociais criar e interrogar estatisticamente dados coletados de grandes amostras (tais como taxas de criminalidade) e, então, usando índices (como idade, gênero e 'raça'), descobrir associações - por exemplo, que o comportamento criminoso é mais comum nas 'classes sociais mais baixas’. A partir disso, não foi difícil dar o salto conceitual para, por exemplo, ver 'o pobre' como coletivamente mais propenso à criminalidade. E, em seguida, foi muito fácil dar um passo além e transformar essas associações encontradas em dados agregados em evidências de 'predisposições' individuais (por exemplo, em relação ao crime, ao suicídio e à insanidade). (tradução nossa).

Sob uma perspectiva crítica, que destaca "a importância da Universidade na construção dos projetos de país e na criação de pensamento crítico e de longo prazo" (SANTOS, 2011, p. 23), o presente artigo defende a relevância do ensino e emprego das abordagens qualitativas em Psicologia, levando em consideração o contexto atual de lutas pelos Direitos Humanos e as reações de ameaça a esses direitos basilares. Além de instrumentalizar os alunos para o fazer científico, as experiências de ensino-aprendizagem apresentadas nesse artigo orientam-se pelo pressuposto da formação cidadã transformadora e inclusiva. Afinal, esse ensino introduz a diversidade de caminhos para o fazer científico e permite ampliar a noção de ciência dos estudantes, bem como a sua capacidade de refletir sobre seu papel social de ouvir e valorizar a diversidade de vozes sociais. Nesse processo, reafirmamos o compromisso ético-político da Psicologia como ciência e profissão e com os Direitos Humanos. 


\section{Apontamentos sobre a relação entre ensino de métodos qualitativos em psicologia e direitos humanos}

A relação entre a Psicologia e o campo dos Direitos Humanos está firmada no Código de Ética Profissional do Psicólogo brasileiro, que estabelece como primeiro princípio fundamental que o psicólogo deve basear sua atuação "no respeito e na promoção da liberdade, da dignidade, da igualdade e da integridade do ser humano, apoiado nos valores que embasam a Declaração Universal dos Direitos Humanos" (CONSELHO FEDERAL DE PSICOLOGIA, 2005, p. 7). Vale destacar que essa perspectiva do Conselho Federal de Psicologia coaduna-se com uma perspectiva crítica e engajada da Universidade, cujo valor social, ligado à produção do conhecimento como um bem público, sobrepuja o valor real, ligado à produtividade e à alocação de recursos financeiros públicos ou privados (SANTOS, 2011).

Em consonância com esse compromisso social e ético, Direitos Humanos tem sido tema de diversos debates e produções acadêmicas em Psicologia (e.g., BOCK; GIANFALDONI, 2010; SCHWEDE; BARBOSA; SCHRUBER-JUNIOR, 2008; ROSATO, 2011; MAIA, 2014; RODRIGUES; CRUZ, 2013; GONÇALVES ET AL., 2017; BICALHO ET AL., 2009). Entre esses autores, Bock e Gianfaldoni (2010) e Bicalho et al. (2009) tratam especificamente da inserção dessa temática na formação em Psicologia.

Bock e Gianfaldoni (2010) debatem a presença da temática dos Direitos Humanos na graduação em Psicologia a partir do levantamento de publicações e da coleta de dados sobre o currículo dos cursos. Para essa coleta, foi utilizado um questionário online, enviado aos 354 cursos de Psicologia cadastrados em 2008, solicitando informações sobre a inserção de conteúdos relativos aos Direitos Humanos em disciplinas, palestras ou debates, pesquisa, projetos de extensão, entre outras atividades acadêmicas. Foram obtidas respostas de apenas 27 cursos, sendo que nenhum deles apontou a presença, explícita ou não, dos Direitos Humanos em disciplina voltada aos Métodos Qualitativos. Por outro lado, o estudo indicou que os Direitos Humanos, ainda que de modo tímido, geralmente aparecem em atividades mais tradicionais do curso, entre as quais se incluem as disciplinas.

As autoras auxiliam na compreensão da escassez e, ao mesmo tempo, da relevância da educação em Direitos Humanos em geral ao destacarem que é recente, no Brasil, a preocupação com os direitos individuais e sociais. Tal preocupação emerge do período de sistemáticas violações da Ditadura Militar e expande-se diante de uma redemocratização rasa, sem reformas sociais ou econômicas voltadas à maioria da população, e que favoreceu a continuidade das violações de direitos em um cenário neoliberal - em atual intensificação - de "prioridade ao mercado, retração do Estado na prestação de políticas sociais e precarização das relações de trabalho" (BOCK; GIANFALDONI, 2010, p. 99).

Bicalho et al. (2009) também partem da compreensão de que os Direitos Humanos são um objeto constituído socio-historicamente e ressaltam que a construção permanente desses direitos atravessa as diversas práticas da Psicologia, uma vez que estas se revelam "poderosos 
e eficientes processos de subjetivação que forjam existências, vidas, bandidos e mocinhos, heróis, vagabundos e vilões, excluídos e perigosos" (BICALHO et al., 2009, p. 27). Assim, ao assumir o compromisso com uma Psicologia pautada nos Direitos Humanos, é preciso romper com a naturalização desses Direitos na prática e na formação e, por conseguinte, evidenciar que as práticas e modos de produção da ciência psicológica não são isentos, ahistóricos ou neutros. As práticas e métodos psicológicos são essencialmente históricos e políticos, geram efeitos, convocam reflexões e exigem posicionamento. Especificamente no campo da formação, a análise do naturalizado, a ressignificação da diferença e a transformação que caracterizam o exercício do compromisso com os Direitos Humanos ocorrem mediante produção de sentidos, em um aprendizado que jamais se esgota na graduação.

[...] não há previsibilidade nem repetição de ministrações conteudísticas. O aluno dará outros manejos ao pensamento e aos conceitos, potencializando os usos diferenciados de acordo com as necessidades. [...] Formação e aplicação caminham lado a lado, mantendo-se uma tensão permanente entre ação e problematização, por uma Psicologia que não só solucione problemas, mas também os invente. (BICALHO et al., 2009, p. 32)

Nesse mesmo sentido, Bock e Gianfaldoni (2010) alertam que, para consolidar o processo de uma educação em Psicologia orientada pelos Direitos Humanos, é preciso fomentar uma formação contínua e profundamente crítica, a qual permita o envolvimento ativo e criativo em prol desses direitos e torne evidente que todos os sujeitos são sujeitos de direitos, devendo ser valorizados e reconhecidos em sua diferença e pluralidade. Embora o ensino e mesmo o uso de métodos qualitativos ainda não estejam claramente colocados como um dos elos entre a Psicologia e a promoção dos Direitos Humanos, a literatura existente permite traçar os contornos dessa aproximação. Possibilita, ainda, argumentar em defesa da necessidade de evidenciar esse elo desde a graduação, como um tema transversal.

À semelhança do compromisso com os Direitos Humanos, cabe salientar que o fazer científico não é totalmente ensinado, dado que não é simples técnica. Ele exige capacidade de problematização. Esse aspecto torna-se ainda mais premente no emprego das abordagens qualitativas no contexto das epistemologias emergentes. Ao exigirem o abandono dos ideais de neutralidade, objetividade e generalização, essas abordagens requerem que o pesquisador questione o seu envolvimento com aquilo que almeja compreender, bem como os efeitos da pesquisa, posicionando-se de forma ética e política. Parte-se do pressuposto de que as decisões tomadas ao longo da pesquisa, incluindo o modo de fazer, são políticas, na medida em que transformam interesses em decisões com efeitos coletivos (IGNÁCIO; CAVOUR, 2008).

A partir disso, pode ser questionado o lugar dos integrantes da pesquisa, incluindo o pesquisador, e podem ser repensadas as formas de apreensão das realidades pesquisadas. Torna-se central considerar as múltiplas vozes e as dimensões nelas inseridas em dado momento histórico. Se não é possível atingir verdades, as metodologias são voltadas para 
construções de sentido; se o sujeito não pode ser tratado como objeto, submetido a um pesquisador hierarquicamente superior, o papel dos cientistas pode se tornar o de produzir, em parceria com os demais sujeitos envolvidos na pesquisa, um conhecimento que lhes seja útil e acessível, que amplie a capacidade do grupo de compreender e intervir em aspectos da sua realidade. Em outras palavras, trata-se de produzir um conhecimento "que ajude o outro a se fortalecer como sujeito autônomo, capaz de elaborar seu próprio projeto político" (MARTINS, 2004, p. 296) e, afinal, a se reconhecer como sujeito de direitos.

Com o fortalecimento dos sujeitos envolvidos na pesquisa, especialmente os marginalizados, e a valorização da pluralidade de vozes e de sentidos por/com eles produzidos, emerge a oportunidade de criação, de modo compartilhado e corresponsável, de vias de promoção de Direitos Humanos. Sobretudo nessa possibilidade, consolida-se o vínculo entre pesquisa qualitativa e Direitos Humanos.

A literatura oferece exemplos bastante ilustrativos dos aspectos mencionados. Destacase aqui a contribuição de Ignácio e Cavour (2008), que expõem o instrumento da restituição como modo de possibilitar a inclusão de todos os sujeitos afetados pela pesquisa em todas as etapas. Nesse estudo, no campo da Psicologia Jurídica, a restituição, em oposição à devolutiva, representa uma forma de construção coletiva dos resultados de uma pesquisaintervenção, na qual os participantes coconstroem inclusive os resultados e as interpretações finais, apropriando-se do processo de pesquisar e do papel político de construção do conhecimento.

Em face disso, compreende-se que a opção por uma abordagem qualitativa questionadora do status quo e investigações dessa natureza podem favorecer a reflexão sobre a dimensão ética e social da atuação e, portanto, do lugar do pesquisador-psicólogo no sentido da promoção de Direitos Humanos. Isso se expressa tanto em transformações diretas de realidades pesquisadas quanto no fornecimento, a partir das reflexões favorecidas pelo processo de pesquisa, de recursos e questionamentos para posturas e atuações mais críticas, emancipatórias e, assim, também ativamente comprometidas com a garantia desses direitos.

Argumentamos, portanto, que a associação entre o ensino e o emprego de abordagens qualitativas com os Direitos Humanos, assim como o compromisso entre a Psicologia e os Direitos Humanos, é uma construção que deve ser reafirmada a cada decisão tomada no decorrer da investigação e dos diferentes níveis de formação em Psicologia. No contexto da graduação, o fomento às reflexões a respeito da aproximação possível e necessária entre pesquisa qualitativa e Direitos Humanos pode ser alcançado, por exemplo, ao se discutir os fundamentos das epistemologias emergentes que direcionam a pesquisa à efetivação desses direitos basilares, tais como a análise situada socio-historicamente e as noções de diversidade de vozes, emancipação, empoderamento, restituição e transformação social. É também primordial não somente apresentar possibilidades de emprego das metodologias qualitativas que viabilizam a aproximação com os Direitos Humanos, mas oferecer oportunidades e orientação para que graduandos trilhem e (re)inventem caminhos pelos quais assumirão o lugar de pesquisadores e profissionais comprometidos com os Direitos Humanos, em um processo de aprendizagem e crítica constantes. 
Para que isso ocorra, deve-se priorizar o estímulo à abertura dos alunos aos diversos modos de fazer ciência. Isso inclui o entendimento das diferenças em relação às abordagens orientadas pelo paradigma positivista e a adoção de uma visão contextualizada das realidades pesquisadas. Os paradigmas emergentes e a apropriação de valores que sustentam o enfoque qualitativo implicam que

Aprendizes devem, primeiramente, ser ressocializados da exposição anterior e geralmente intensa à noção de ciência. [...] Os estudantes devem passar a reconhecer diferenças entre os paradigmas [...] e, nesse contexto, dominar tanto métodos qualitativos quanto quantitativos. [...] Eles também devem ser auxiliados a entender a história e a estrutura social, política, cultural, econômica, étnica e de gênero que cercam suas investigações e a incorporar os valores de altruísmo e empoderamento em seu trabalho. (GUBA; LINCOLN, 1994, p. 115, tradução nossa).

\section{Relato de experiências: envolvendo graduandos na diversidade do fazer científico}

Com o propósito de sensibilizar sobre a diversidade do fazer científico e das vozes sociais, bem como sobre a necessidade de se implicar politicamente para promover os Direitos Humanos, a disciplina ministrada em uma instituição federal de ensino superior de Minas Gerais é estruturada de forma a abarcar o histórico de surgimento das metodologias qualitativas nas Ciências Humanas e na Psicologia, a ética no emprego desses métodos, a relação com a abordagem quantitativa e a importância da pesquisa na formação do psicólogo, bem como os principais aspectos de algumas modalidades de pesquisa e métodos de coleta e análise de dados qualitativos. Prioriza-se o envolvimento direto dos discentes na produção do conhecimento científico, mediante, entre outras estratégias didáticas, a formulação de projetos de pesquisa fictícios, a avaliação de paineis de um evento de divulgação científica da Universidade e a realização de entrevistas com discentes de laboratórios de pesquisa ou estagiários que utilizam métodos qualitativos.

A proposta aqui apresentada passa por reformulações ao longo dos semestres, com base nas contribuições das docentes que assumem a condução da disciplina, nas sugestões dos estudantes e na presença de monitoras que participam ativamente da construção dos recursos didáticos. Essa pluralidade de aportes visa permitir o amadurecimento metodológico e reflete a policromia e o aspecto dinâmico das metodologias qualitativas. Vale notar que a metodologia aplicada na elaboração do plano de ensino mescla-se com os métodos ensinados em sala de aula, exercitando a abordagem qualitativa no processo de ensino-aprendizagem.

Com base nos eixos estruturantes que constam na Resolução CNE/CES n 05, de 15 de março de 2011 (BRASIL, 2011), que institui as Diretrizes Curriculares Nacionais para os cursos de Graduação em Psicologia, pode-se considerar que o ensino dessa disciplina integra, sobretudo, o eixo de "Fundamentos teórico-metodológicos". Isso se dá uma vez que a 
disciplina direciona-se à garantia da "apropriação crítica do conhecimento disponível, assegurando uma visão abrangente dos diferentes métodos e estratégias de produção do conhecimento científico em Psicologia” (BRASIL, 2011, p. 2).

Especificamente no projeto da matriz curricular do curso em questão (UNIVERSIDADE FEDERAL DE MINAS GERAIS, 2009a), prevê-se a oferta Métodos Quantitativos como disciplina obrigatória do primeiro período do curso, porém a aprovação nessa disciplina não é pré-requisito para cursar a disciplina de Métodos Qualitativos, obrigatória do segundo período, e sim para a matrícula em Estatística Aplicada à Psicologia, também alocada no segundo período da graduação. A ementa de Métodos Qualitativos sintetiza os pontos a serem abordados como: "Pesquisa qualitativa: histórico e campos de aplicação. Dados qualitativos: coleta, análise e apresentação. Ética e pesquisa qualitativa" (UNIVERSIDADE FEDERAL DE MINAS GERAIS, 2009b, p. 3).

Nesse contexto inicial do curso, ao se deparar com a responsabilidade de lecionar métodos qualitativos, alguns questionamentos surgem. Como ensinar sobre pesquisa em Psicologia para alunos que ainda desconhecem a diversidade de aportes teóricos e campos de atuação presentes na Psicologia? Quais propostas pedagógicas poderiam ser construídas visando estimular o interesse pelo fazer científico? De que maneira seria possível contextualizar as tensões e os embates presentes no atual cenário da Ciência brasileira? E, fundamentalmente, como demonstrar a relevância de se continuar pesquisando em Psicologia, utilizando métodos qualitativos, mesmo diante de tantos obstáculos para o fomento e desenvolvimento desse modo de fazer ciência?

Para abarcar essas questões, divide-se a disciplina de 60 horas/aula em quatro unidades de ensino (Quadro 1). Essa distribuição é uma opção pedagógica, uma vez que alguns desses temas poderiam estar alocados em outras unidades e que, na prática, podem ser aplicados conjuntamente.

Quadro 1 - Conteúdo programático de Métodos Qualitativos em Psicologia

\begin{tabular}{|c|c|c|}
\hline Unidades & Temáticas & Estratégias didáticas* \\
\hline $\begin{array}{l}\text { I. A pesquisa em ciências } \\
\text { sociais e humanas }\end{array}$ & $\begin{array}{l}\text { - Histórico do surgimento das } \\
\text { metodologias qualitativas nas } \\
\text { Ciências Sociais e Humanas; } \\
\text { - Relação entre os métodos } \\
\text { qualitativos e quantitativos: } \\
\text { triangulação e } \\
\text { complementaridade; } \\
\text { - Ética na pesquisa qualitativa; } \\
\text { - Feedback, restituição e construção } \\
\text { da pesquisa com sujeitos } \\
\text { envolvidos; } \\
\text { - Estruturação de projetos de } \\
\text { pesquisa; }\end{array}$ & $\begin{array}{l}\text { - Aulas expositivas; } \\
\text { - Debate sobre ética; } \\
\text { - Discussão online em plataforma } \\
\text { de ensino } \\
\text { - Formulação de um projeto de } \\
\text { pesquisa fictício e simulação de } \\
\text { banca de qualificação. }\end{array}$ \\
\hline
\end{tabular}




\begin{tabular}{|c|c|c|}
\hline & $\begin{array}{l}\text { - A pesquisa na formação do } \\
\text { psicólogo. }\end{array}$ & \\
\hline $\begin{array}{l}\text { II. Modalidades de } \\
\text { pesquisa }\end{array}$ & $\begin{array}{l}\text { - Estudo de caso; } \\
\text { - Etnografia e netnografia; } \\
\text { - Pesquisa-ação; } \\
\text { - Observação participante; } \\
\text { - Uso de vídeo, imagem, som e } \\
\text { outros recursos. }\end{array}$ & \multirow{2}{*}{$\begin{array}{l}\text { - Palestras de pesquisadores. } \\
\text { - Atividades em grupo: } \\
\text { ○ Fichamento e apresentação } \\
\text { criativa de uma tese ou } \\
\text { dissertação em Psicologia que } \\
\text { utilize uma dessas modalidades } \\
\text { e métodos qualitativas; } \\
\text { ○ Avaliação de paineis e interação } \\
\text { com autores na Semana do } \\
\text { Conhecimento da Universidade; } \\
\text { ○ Entrevista com estagiários de } \\
\text { Psicologia a respeito do uso de } \\
\text { métodos qualitativos na prática } \\
\text { profissional; } \\
\text { ○ntrevista com integrantes de } \\
\text { laboratórios de pesquisa que } \\
\text { utilizam métodos qualitativos } \\
\text { em suas investigações e } \\
\text { observação do seu } \\
\text { funcionamento. }\end{array}$} \\
\hline $\begin{array}{l}\text { III. Métodos de coleta de } \\
\text { dados }\end{array}$ & $\begin{array}{l}\text { - Levantamento bibliográfico; } \\
\text { - Entrevista; } \\
\text { - Grupo focal; } \\
\text { - História de vida e pesquisa } \\
\text { biográfica. }\end{array}$ & \\
\hline $\begin{array}{l}\text { IV. Métodos de } \\
\text { tratamento e análise de } \\
\text { dados }\end{array}$ & $\begin{array}{l}\text { - Análise de conteúdo; } \\
\text { - Análise do discurso. }\end{array}$ & $\begin{array}{l}\text { - Realização de roda de conversa } \\
\text { sobre uso de métodos de } \\
\text { qualitativos com alunos de pós- } \\
\text { graduação convidados. } \\
\text { - Redação de relatórios individuais. }\end{array}$ \\
\hline
\end{tabular}

* As estratégias didáticas variam a cada semestre. Aqui, apresentamos o conjunto de todas as estratégias já utilizadas com o objetivo de demonstrar a diversidade de estratégias que a disciplina permite.

O desafio principal da Unidade I reside na apreensão da metodologia qualitativa como modo legítimo de pesquisa. Os discentes tendem a iniciar a disciplina com a concepção positivista de ciência como única. O arraigamento dessa concepção advém, sobretudo, de terem aprendido, por vezes desde o Ensino Médio, somente esse paradigma e por terem cursado a disciplina Métodos Quantitativos no período precedente. Assim, o percurso histórico da construção dos métodos qualitativos e o rompimento do paradigma positivista (ROMÃO-DIAS, 2013; MARTINS, 2004) ocupam essa etapa inicial do ensino e mostramse fundamentais no decorrer de todo o processo de ensino-aprendizagem, sendo retomados em aulas posteriores.

Busca-se questionar a crença na oposição entre métodos qualitativos e quantitativos, apresentando formas de triangulação de pesquisa e de complementaridade dos métodos (MINAYO; SANCHES, 1993) e respeitando-se a estruturação do desenho da pesquisa (FLICK, 2009). A relação entre o uso desses métodos em projetos de pesquisa e sua submissão aos Comitês de Ética em Pesquisa perpassa a divisão epistemológica entre Ciências Naturais e Ciências Humanas e Sociais (DEMO, 1987). O debate recente (BARBOSA; SOUZA, 2008; CONCONE, 2008; SANTOS; JEOLÁS, 2015), que culminou 
na aprovação da Resolução CNS no 510/2016 (BRASIL, 2016), é dramatizado em sala por meio da utilização dos documentos trocados entre as Entidades que construíram a proposta e a Comissão Nacional de Ética em Pesquisa (CONEP). Um quadro comparativo elaborado por monitora ${ }^{3}$, no qual constam as mudanças advindas com a referida resolução e os pontos ainda não contemplados, é apresentado e discutido com os discentes.

A importância da realização do feedback da pesquisa e sua produção conjunta com os sujeitos que dela participam (IGNÁCIO; CAVOUR, 2008; TAVARES; FRANCISCO, 2016) e a estruturação formal de um projeto de pesquisa (DESLANDES, 2013) também são pontos contemplados na primeira unidade. Por fim, a pesquisa na formação do psicólogo (NOVO, 1999) e o rompimento da oposição entre profissionais teóricos e práticos são aspectos amplamente debatidos, a fim de que os alunos possam compreender a importância de assumir a postura de pesquisadores independentemente do local de trabalho no qual vierem a atuar. Desta forma, busca-se denotar a aproximação necessária entre o campo acadêmico e os profissionais na ponta mediante a construção de projetos de pesquisas voltados para a qualificação da atividade reflexiva, atualizada e crítica do psicólogo nos diversos campos de atuação.

Na Unidade II, são abordados alguns modos de pesquisa. A ampla gama de métodos qualitativos, o contínuo processo de criação de novas modalidades e as subdivisões internas em cada metodologia, aliados à reduzida carga horária da disciplina, exigem das docentes a limitação dos temas a serem abordados. Algumas perspectivas metodológicas podem ser acrescentadas ou retiradas de acordo com a proximidade teórica da professora ou mesmo dependendo da disponibilidade da participação de convidados. Desta forma, a lista de temáticas pode sofrer modificações. De modo geral, têm sido mantidas as seguintes temáticas: Estudo de caso (PERES; SANTOS, 2005; ALVES-MAZZOTTI, 2006), PesquisaAção (RIZZINI; CASTRO; SARTOR, 1999), Etnografia (NEVES, 2006; BEZERRA, 2010), Observação participante (MAY, 2004; VALLADARES, 2007; MIZRAHI, 2007), Netnografia (BRAGA, 2013), outros recursos como vídeo, fotografia, história em quadrinhos e filmes (LOIZOS, 2003; BEIRAS et al., 2007).

Na Unidade III, acerca dos modos de coleta de dados, destacamos as seguintes modalidades: Levantamento bibliográfico (ALVES, 1992; FLICK, 2013), Entrevista (GASKELL, 2003), Grupo Focal (KIND, 2004; GATTI, 2005), História de vida e Pesquisa biográfica (QUEIROZ, 1988; BARROS; SILVA, 2002; MATOS-SILVA, 2013).

A Unidade IV refere-se ao tratamento dos dados, concluindo o percurso de elaboração de um projeto de pesquisa. Em decorrência da complexidade de ensinar a análise de dados sem efetivamente realizá-la em uma turma composta em média por 70 alunos, restringe-se a escolha por dois caminhos apenas: Análise de conteúdo temática (GOMES, 2013) e Análise do discurso (GILL, 2003; PILLA; QUADROS, 2009).

Ao longo de toda a disciplina, são empregadas várias estratégias didáticas que envolvem diretamente os discentes nas etapas da produção do conhecimento científico. Os principais objetivos de algumas dessas estratégias são apresentados no Quadro 2. 
Quadro 2 - Algumas estratégias didáticas e seus objetivos

\begin{tabular}{|c|c|}
\hline Estratégia pedagógica & Objetivos \\
\hline $\begin{array}{l}\text { Fichamento e apresentação criativa de uma tese ou } \\
\text { dissertação em Psicologia que utilize metodologias } \\
\text { qualitativas dentre as que compõem o programa } \\
\text { - material de apoio: roteiro de fichamento }\end{array}$ & $\begin{array}{l}\text { - Permitir a familiarização com buscadores } \\
\text { confiáveis para pesquisas acadêmicas; } \\
\text { - Estimular a apropriação crítica e criativa do } \\
\text { conteúdo analisado. }\end{array}$ \\
\hline $\begin{array}{l}\text { Entrevista com estagiários de Psicologia a respeito } \\
\text { do uso de métodos qualitativos na prática } \\
\text { profissional } \\
\text { - material de apoio: roteiro de entrevista e } \\
\text { treinamento para entrevista realizado pela monitora }\end{array}$ & $\begin{array}{l}\text { Possibilitar reflexões sobre as possibilidades e as } \\
\text { implicações do uso de métodos qualitativos na } \\
\text { prática profissional; } \\
\text { - Reduzir a distância entre a disciplina teórica ( } 2^{\circ} \\
\text { período) e a atuação profissional (a partir do } 8^{\circ} \\
\text { período); } \\
\text { - Aprofundar a discussão sobre a necessidade de } \\
\text { uma atitude científica e comprometida com os } \\
\text { Direitos Humanos nos diversos campos de } \\
\text { atuação profissional em Psicologia. }\end{array}$ \\
\hline $\begin{array}{l}\text { Entrevista com integrantes e observação do } \\
\text { funcionamento de laboratórios de pesquisa que } \\
\text { utilizam métodos qualitativos em suas investigações } \\
\text { - material de apoio: roteiro de entrevista e } \\
\text { treinamento para entrevista realizado pela monitora }\end{array}$ & \multirow[t]{3}{*}{$\begin{array}{l}\text { Aproximar os discentes da produção científica } \\
\text { que ocorre na Universidade, especialmente } \\
\text { aquela amparada na abordagem qualitativa. } \\
\text { - Aproximar a pós-graduação da graduação. }\end{array}$} \\
\hline $\begin{array}{l}\text { Avaliação de trabalhos de pesquisa e interação com } \\
\text { apresentadores na Semana do Conhecimento da } \\
\text { Universidade } \\
\text { - material de apoio: ficha de avaliação }\end{array}$ & \\
\hline $\begin{array}{l}\text { Realização de roda de conversa com pesquisador } \\
\text { convidado }\end{array}$ & \\
\hline $\begin{array}{l}\text { Formulação de um projeto de pesquisa fictício e } \\
\text { simulação de banca de qualificação } \\
\text { - material de apoio: modelo de projeto, lista de } \\
\text { perguntas para arguição }\end{array}$ & $\begin{array}{l}\text { - Envolver os discentes no processo formal de } \\
\text { investigação científica; } \\
\text { - Debater sobre a adequação da proposta } \\
\text { apresentada de maneira participativa e } \\
\text { construtiva. }\end{array}$ \\
\hline
\end{tabular}

Ilustramos a seguir a dinâmica de utilização dessas estratégias. O fichamento de uma dissertação ou tese em Psicologia é realizado em grupos e a área da Psicologia é de livre escolha dos alunos. $\mathrm{O}$ título da dissertação ou tese é informado à monitora para verificação da adequação do material escolhido e para que não se repitam os trabalhos. $O$ trabalho não pode ter sido defendido na mesma Universidade na qual a disciplina é lecionada. Um roteiro com orientações sobre o que deve ser avaliado na leitura é disponibilizado para os alunos.

Cada tema é apresentado na seguinte sequência: exposição do tema pela docente, apresentação pelo grupo com duração de cerca de vinte minutos e debate com a turma. $\mathrm{O}$ formato de apresentação não é estipulado, mas o uso da criatividade a partir do uso ou elaboração de vídeos, músicas, encenações, dinâmicas de grupo com a turma, é valorizado. 
Nesse momento, surgem dúvidas sobre a adequação do método empregado na pesquisa, a respeito de mudanças e adequações realizadas pelo pesquisador e também em relação à aplicabilidade da metodologia ao problema de pesquisa.

As entrevistas com estagiários em Psicologia são realizadas em grupos. Cada grupo escolhe uma área da Psicologia e entrevista dois estagiários dessa área. O critério de seleção é que o estagiário já tenha utilizado ou utilize algum método qualitativo em seu trabalho. $\mathrm{O}$ preparo para a realização das entrevistas inclui uma oficina prática conduzida pela monitora, com o uso de técnicas de desempenho de papel. A prática é reforçada pela teoria sobre entrevista, na aula correspondente. Os grupos recebem um roteiro semi-estruturado de entrevista, o qual adaptam a partir de leituras sobre o campo escolhido. As entrevistas realizadas são transcritas e analisadas, com o apoio da monitora, para gerar categorias de análise de conteúdo. O relatório de pesquisa inclui o levantamento bibliográfico sobre o campo, a descrição do método, a análise das entrevistas e as conclusões do grupo sobre o uso de métodos qualitativos na atuação psicológica, com destaque para as questões éticas e implicações para as pessoas ou grupos atendidos por esses estagiários.

A atividade em laboratórios de pesquisa também é realizada em grupos. Os discentes observam o funcionamento de um laboratório ou grupo de pesquisa em Psicologia e realizam uma entrevista com um de seus membros. O critério de seleção é a utilização de métodos qualitativos na pesquisa. Os alunos também devem ler ao menos uma produção acadêmica elaborada pela equipe que poderá ser indicada pelo entrevistado. O trabalho pode ser realizado em laboratório ou grupo de pesquisa de outro departamento da Universidade, desde que a proposta seja interdisciplinar e ao menos um integrante seja do campo da Psicologia. A escolha do laboratório deve ser informada à monitora, para que não ocorra repetição de locais e para garantir diversidade de áreas. Em sala de aula, os grupos falam sobre os laboratórios que pesquisaram em uma roda de conversa.

A Semana do Conhecimento da Universidade Federal de Minas Gerais é um evento anual organizado pelas Pró-Reitorias de Pesquisa e de Extensão da instituição, tendo o propósito de compartilhar e refletir sobre os conhecimentos produzidos por alunos de graduação da Universidade. Os apresentadores são discentes envolvidos com a Iniciação Científica e projetos de extensão, os quais obrigatoriamente têm que produzir um painel para relatar os projetos que desenvolveram ou vêm desenvolvendo. Os alunos da disciplina de métodos qualitativos, distribuídos em grupos, utilizam a mesma ficha de avaliação dos professores avaliadores para visitar os paineis e endereçar perguntas aos apresentadores de três trabalhos à sua escolha. Os critérios para a seleção dos paineis são: que sejam trabalhos de iniciação científica em Psicologia e que tenham utilizado metodologia qualitativa. Posteriormente, em sala, é realizada uma roda de conversa, na qual os grupos dialogam, com toda a turma, sobre os trabalhos que analisaram.

A formulação do projeto de pesquisa é a atividade final da disciplina. É realizada em grupos, divididos em seis campos da Psicologia. A cada semestre os campos podem se alternar, a fim de abarcar áreas diversas. Pode-se citar como exemplos: Psicologia Clínica, Gerontologia/Psicologia do Envelhecimento, Psicologia Organizacional, Psicologia Escolar, Psicopedagogia, Psicologia do Esporte, Psicologia Hospitalar, Psicologia das Emergências e 
Desastres, Psicologia do Trabalho, Psicologia Comunitária, Psicologia Jurídica e Psicologia do Desenvolvimento. As normas para a elaboração do projeto são enviadas para os discentes e seguem a estruturação de projeto de pesquisa (DESLANDES, 2013), incluindo a exigência da construção do instrumento de coleta de dados, quando necessário, e do Termo de Consentimento Livre e Esclarecido, conforme os critérios estabelecidos na Resolução $\mathrm{n}^{\circ}$ 510/2016 do Conselho Nacional de Saúde (BRASIL, 2016).

O grupo apresenta o projeto em uma atividade de simulação de banca de qualificação, composta por três alunos, os quais são escolhidos voluntária ou aleatoriamente, e pela docente. Cada membro da banca recebe uma cópia do projeto e uma lista de perguntas que poderá orientar a arguição. Após a apresentação pelos integrantes do grupo, a banca poderá fazer perguntas, iniciando um diálogo com os discentes. Avalia-se que a experiência com essa metodologia é enriquecedora para os discentes, pois, apesar de inicialmente demonstrarem preocupação com a atividade (tanto os membros do grupo quanto os participantes da banca), rapidamente compreendem que a proposta não é punitiva, e sim de aprendizagem. A mudança de postura do primeiro para o segundo grupo é evidente, indicando o engajamento dos alunos.

\section{Reflexões sobre a experiência: a perspectiva docente e a discente}

A alocação da disciplina no segundo período da formação apresenta alguns impasses e potencialidades. Como vantagem, emerge a possibilidade de apresentar a diversidade das estratégias metodológicas da Psicologia enquanto ciência e profissão, de propiciar o questionamento sobre a produção do conhecimento, bem como de estimular a inserção dos discentes nos projetos de pesquisa da Universidade. Por outro lado, o desafio traduz-se na incipiência do conhecimento, por parte dos alunos, a respeito da diversidade presente na Psicologia e do próprio saber psicológico, o que gera dificuldade na compreensão da leitura de artigos, teses e dissertações, bem como dificuldade de estabelecer rapport ao realizar uma entrevista na prática.

Como desdobramento, além de a disciplina promover o primeiro contato com essa amplitude de abordagens e de áreas de atuação, as estratégias didáticas possibilitam reflexões sobre como o engajamento social do pesquisador é inerente à sua prática profissional em uma perspectiva orientada pelos Direitos Humanos. As experiências demonstram a necessidade de criar e repensar ferramentas de ensino que, tais como as apresentadas, visam permitir que os estudantes exercitem o debate e o fazer científicos desde o princípio da graduação. Alguns relatos de alunos em avaliações da disciplina ${ }^{4}$ indicam os potenciais impactos dessas estratégias metodológicas para a formação em Psicologia.

A disciplina foi muito bem elaborada e útil para meu aprendizado. Foi muito rico o aprendizado em relação aos métodos qualitativos e aprendizado acadêmico. 
Acredito que a disciplina seja fundamental na formação em psicologia, tanto para atuação profissional quanto para a pesquisa.

Foi de grande importância conhecer mais a fundo o campo das metodologias qualitativas, a interdependência das mesmas com outras áreas do conhecimento e a oportunidade que elas oferecem de conhecer de forma mais minuciosa o objeto de estudo. Achei interessante a complementação que a metodologia quali proporciona à quanti, vice-versa, visto que eu tinha o estereótipo de ambos campos como essencialmente independentes.

Nesses dois períodos iniciais, acredito que a disciplina foi uma das mais úteis e bem apresentadas. Acumulei muitos aprendizados e acredito que será muito útil em minha formação.

Minha objetividade não fez da disciplina uma experiência tão prazerosa assim. Mas foi importante nas reflexões sobre os métodos (quanti e quali) e o status de linguagem que agregam e/ou adquirem. Tudo isso para dizer que a disciplina está impecável.

Achei o trabalho maravilhoso, deu muito trabalho, mas foi muito bom aplicar o que aprendemos nas aulas e podermos fazer um trabalho com uma forma mais acadêmica.

A disciplina foi em geral muito boa, proporcionando base teórica e possibilidade de ver e colocar na prática, como no caso da entrevista e revisão bibliográfica.

Essa disciplina me faz ver o mundo de uma maneira mais crítica sobre as relações, as coisas subjetivas.

A presença de especialistas no assunto abordado, como foi o caso da aula de netnografia e como seria o caso da aula de análise de discurso desperta maior interesse e contribui para o aprendizado (já que permite maior dinamicidade).

Assim, espera-se que essa atitude científica ajude a fortalecer o compromisso ético com a promoção dos Direitos Humanos, beneficiando todo o percurso acadêmico e profissional dos estudantes.

\section{Considerações finais}

Este artigo apresentou experiências de ensino-aprendizagem de métodos qualitativos em um curso de graduação em Psicologia como uma estratégia para ampliar a concepção de ciência dos estudantes a partir das epistemologias emergentes e da legitimidade dos métodos qualitativos para produção de conhecimento psicológico. Essa discussão epistêmico- 
metodológica é aqui alinhada à premissa de que é necessário compreender o contexto local em sua construção social e histórica para a promoção dos Direitos Humanos como compromisso ético do profissional psicólogo.

Destarte, este estudo contribui para a literatura nacional sobre o ensino de métodos qualitativos, sugerindo estratégias didáticas para docentes que buscam ensejar uma formação ampliada dos alunos, a qual não se restrinja ao aprendizado de técnicas usadas de forma descontextualizada. Em relação à relevância social, incentiva o desenvolvimento de produções científicas com o emprego de metodologias qualitativas sob a premissa de Direitos Humanos, tida como fundamental para evitar retrocessos no campo da Psicologia. De modo mais amplo, esse incentivo pode ser essencial para a construção de uma cultura de visibilização, valorização e efetivação desses direitos. Considera-se que retrocessos e invisibilidades podem advir da importação de modelos e teorias que não se aplicam à realidade socio-histórica brasileira (SANTOS, 2011) e do uso acrítico dos métodos de pesquisa, sejam qualitativos ou quantitativos.

Além da importação acrítica de modelos na produção científica, o contexto atual de radicalismo político no Brasil também apresenta desafios para uma formação em Psicologia orientada aos Direitos Humanos. Estudo recente em 27 países aponta, por exemplo, que 32\% dos brasileiros - frente a uma média global de $24 \%$ — acreditam não valer a pena conversar com pessoas com visões políticas diferentes das suas (GOMES; BRIDI; LARA, 2019). Tal radicalismo implica na discriminação e exclusão de vozes dissidentes, comprometendo principalmente a visibilidade e o reconhecimento daqueles que mais sofrem por não terem seus direitos garantidos.

No campo da pesquisa, destacam-se as ameaças ao avanço de estudos dessa natureza com base na retirada contínua de investimentos das universidades públicas, como mostram os sucessivos cortes orçamentários para Ciência e Tecnologia (C\&T) desde 2014 (SBPC, 2019). Para citar um exemplo atual, em 2015 o orçamento total previsto para o CNPq, com cortes de 38\% em relação a 2014, foi de R\$ 1,96 bilhões (CNPQ, 2019). Para o ano de 2019, o governo propôs um orçamento de $\mathrm{R} \$ 1$ bilhão (CNPQ, 2018), valor inferior aos $\mathrm{R} \$ 1,42$ bilhões de 2018 (PORTAL, 2019) e compatível com o orçamento do CNPq em 2007 (de 1,18 bilhões de reais) (MOREIRA, 2017).

No caso da Psicologia e sua pluralidade paradigmática (ABIB, 2009), com diversos pontos de interseção com as Ciências Naturais, abre-se o questionamento sobre quais áreas da Psicologia permanecerão recebendo apoio para seu desenvolvimento nesse contexto de desmonte. Uma visão predominantemente funcionalista sobre os modos de investigação científica poderá afetar diretamente o fomento à pesquisa no âmbito das Ciências Humanas e Sociais que se orientam por paradigmas emergentes. Equivale dizer que a Psicologia poderá não ser afetada de forma homogênea: alguns campos mais próximos dos estudos das Ciências Naturais e adeptos de metodologias quantitativas e experimentais poderão sofrer menos com a implementação da perspectiva funcionalista de ciência como critério para acessar financiamento governamental. Essa perspectiva já foi utilizada em outros momentos da história para deslegitimar e deter o avanço de abordagens qualitativas (WILLIG; STAINTON-ROGERS, 2008). 
Assim, uma agenda de pesquisa que se abre a partir da reflexão sobre o ensino de métodos qualitativos, sob a premissa das epistemologias emergentes e da lente de defesa dos Direitos Humanos, também responde ao crescente discurso sobre o financiamento de pesquisa pela iniciativa privada. Que vozes essa pesquisa ouviria? Quais seriam os impactos sobre as diferentes áreas da Psicologia, já que algumas podem ser mais atraentes que outras para o financiamento empresarial? Como seriam financiadas as pesquisas que, direta ou indiretamente, estivessem relacionadas à denúncia de violações e defesa dos Direitos Humanos, bem como à construção de práticas e posicionamentos críticos de profissionais da Psicologia nos mais diversos contextos?

Por conseguinte, no atual cenário político nacional, com diversos cortes na área da Educação e da Ciência, provocar nos alunos o interesse em desenvolver pesquisa - e, ainda mais, utilizando métodos qualitativos que ressoem as vozes das minorias e dos grupos marginalizados - pode se tornar um ato de resistência em prol do exercício crítico de uma Psicologia pautada nos Direitos Humanos.

\section{Notas}

1. Agradecemos ao Programa de Monitoria da Graduação (PMG), da Pró-Reitoria de Graduação da UFMG (PROGRAD), pela concessão de bolsa acadêmica à terceira autora por meio do Edital no01/2017 para atuação como monitora na disciplina de Métodos Qualitativos em Psicologia.

2. O termo naturalista, aqui, se refere à perspectiva de aplicação do paradigma das ciências naturais às ciências humanas e sociais sem considerar as especificidades do objeto de estudo dessas (D’AGOSTINO, 2010).

3. Agradecemos à monitora bolsista do Programa de Monitoria da Graduação da Universidade, Juliana Silveira Di Ninno, pela elaboração do referido quadro.

4. Avaliações anônimas realizadas no último dia de aula dos semestres 2017-2 e 2018-1, como fechamento da disciplina.

5. Agradecemos às valiosas sugestões de melhorias para o texto recebidas de dois (duas) avaliadores(as) ad hoc.

\section{Referências}

ABIB, J. A. D. Epistemologia pluralizada e história da psicologia. Scientiæ Studia, v. 7, n. 2, p. 195-208, 2009.

ALVES, A. J. A "revisão da bibliografia" em teses e dissertações: meus tipos inesquecíveis. Cad. Pesq. São $\begin{array}{lllllll}\text { Paulo, } & \text { n. } & 81, & \text { p. } & 56-60, & 1992 . & \text { Disponível }\end{array}$ <http://publicacoes.fcc.org.br/ojs/index.php/cp/article/view/990>. Acesso em 18 abr. 2019.

ALVES-MAZZOTTI, A. J. Usos e abusos dos estudos de caso. Cadernos de Pesquisa, v. 36, n 129, p. 637651, set./dez. 2006. Disponível em: 〈http://www.scielo.br/pdf/cp/v36n129/a0736129.pdf〉. Acesso em 18 abr. 2019.

ANTUNES, A. N. Formação académica em metodologia qualitativa: Prática pedagógica em Psicologia da Educação. Revista Lusófona de Educação, v. 36, p. 147-161, 2017. Disponível em: <http://www.adipsieduc.pt/wp-content/uploads/2017/03/Antunes-2017.pdf>. Acesso em 18 abr. 2019.

BARBOSA, D. R.; SOUZA, M. P. R. Ética na pesquisa qualitativa: reflexões sobre privacidade, anonimato e confidencialidade. In: GUERRIERO, I. C. Z.; SCHMIDT, M. L. S.; ZICKE (Orgs.). Ética nas pesquisas em ciências humanas e sociais na saúde. São Paulo: Aderaldo \& Rothchild, 2008.

BARROS, V. A. de; SILVA, L. R. da. A pesquisa em História de Vida. In : GOULART, I. B. (Org.) Psicologia do Trabalho e Organizacional: teoria, pesquisa e temas correlatos. 1 ed. São Paulo: Casa do Psicólogo, 2002, p. 133-146. 
BEIRAS, A.; LODETTI, A.; CABRAL, A. G.; TONELI, M. J. F.; RAIMUNDO, P.. Gênero e super-heróis: o traçado do corpo masculino pela norma. Psicologia e Sociedade (Impresso), v. 19, p. 62-67, 2007. Disponível em: <http://www.scielo.br/pdf/psoc/v19n3/a10v19n3.pdf>. Acesso em 17 jan. 2018

BEZERRA, A. K. G. A pesquisa etnográfica e as especificidades da observação participante. Vinheta, v. 01, p. 01-18, 2010.

BICALHO, P. P. G. de; CASSAL, L. C. B.; MAGAlHÃES, K. C.; GERALDINI, J. R. Formação em Psicologia, Direitos Humanos e Compromisso Social: A produção micropolítica de novos sentidos. Boletim $\begin{array}{llllll}\text { Interfaces da } & \text { Psicologia } & \text { da } & \text { UFRRJ. } & 2009 . & \text { Disponível }\end{array}$ <http://www.ufrrj.br/seminariopsi/2009/boletim2009-2/bicalho.pdf>. Acesso em 18 abr. 2019.

BOCK, A. M. B.; GIANFALDONI, M. H. T. A. Direitos humanos no ensino de Psicologia. Psicol. Ensino \& Form., v. 1, n. 2, p. 97-115, 2010. Disponível em: <http://pepsic.bvsalud.org/scielo.php?script=sci_ arttext\&pid=S2177-20612010000200009>. Acesso em 18 abr. 2019.

BRAGA, A. Netnografia: compreendendo o sujeito nas redes sociais. In: NICOLACI-DA-COSTA, A. M.; ROMÃO-DIAS, D. (Orgs.). Qualidade faz diferença: métodos qualitativos de pesquisa para psicologia e áreas afins. Rio de Janeiro e São Paulo: PUC-Rio e Edições Loyola, 2013, p. 171-198.

BRASIL. Ministério da Educação - Conselho Nacional de Educação. Resolução CNE/CES n 05 , de 15 de março de 20011. Institui as Diretrizes Curriculares Nacionais para os cursos de graduação em Psicologia, estabelecendo normas para o projeto pedagógico complementar para a Formação de Professores de Psicologia. 2011.

Conselho Nacional de Saúde. Resolução no 510, de 07 de abril de 2016. Dispõe sobre as normas aplicáveis a pesquisas em Ciências Humanas e Sociais cujos procedimentos metodológicos envolvam a utilização de dados diretamente obtidos com os participantes... 2016.

BURREL, G.; MORGAN, G. Sociological paradigms and organisational analysis: Elements of the sociology of corporate life. Reino Unido: Heinemann, 1979.

CONCONE, M. H. V. B. A pesquisa e a ética. In: GUERRIERO, I. C. Z.; SCHMIDT, M. L. S.; ZICKE (Orgs.). Ética nas pesquisas em ciências humanas e sociais na saúde. São Paulo: Aderaldo \& Rothchild, 2008.

CONSElHO FEDERAL DE PSICOLOGIA - CFP. Código de Ética Profissional do Psicólogo. 2005. Disponível em: <https://site.cfp.org.br/wp-content/uploads/2012/07/codigo-de-etica-psicologia.pdf>. Acesso em 18 abr. 2019.

CNPQ - CONSELHO NACIONAL DE DESENVOLVIMENTO CIENTÍFICO E TECNOLÓGICO. Orçamento do CNPq para 2019 é revisto. Disponível em <http://www.cnpq.br/web/guest/noticiasviews//journal_content/56_INSTANCE_a6MO/10157/6459598>. Acesso em 21 abr. 2019.

CNPQ - CONSELHO NACIONAL DE DESENVOLVIMENTO CIENTÍFICO E TECNOLÓGICO. Séries Históricas até 2015. Disponível em <http://cnpq.br/series-historicas>. Acesso em 21 abr. 2019.

D’AGOSTINO, F. Social sciences, epistemology of. In: DANCY, J.; SOSA, E.; STEUP, M. (Eds.). A Companion to Epistemology. 2 ed. Chichester: Wiley-Blackwell, 2010.

DEMO, P. Introdução ao ensino da metodologia da ciência. DEMO, P. Introdução à metodologia da ciência. São Paulo: Atlas, 1987, p.13-28.

DESLANDES, S. F. A construção do projeto de pesquisa. In: MINAYO, M. C. de S. (Org.). Pesquisa social: teoria, método e criatividade. Rio de Janeiro: Vozes, 2013, p. 31-60.

FLICK, U. Desenho da pesquisa qualitativa. Porto Alegre: Artmed, 2009, p. 95-104.

Leitura e Revisão de Literatura. In: Introdução à Metodologia de Pesquisa. Porto Alegre: Penso, 2013, p. 41-52.

GASKELL, G. Entrevistas individuais e grupais. In: BAUER, M. W.; GASKELL, G. Pesquisa Qualitativa com texto, imagem e som: um manual prático. $2^{\circ}$ ed. Petrópolis: Vozes, 2003, p. 64-89. 
GATTI, B. A. Pesquisas com grupos focais. In: GATTI, B. A. Grupo focal na pesquisa em ciências sociais e humanas. Brasília: Líber, 2005, p. 57-66.

GIBSON, S.; SULLIVAN, C. Teaching Qualitative Research Methods in Psychology: an introduction to the special issue. Psychology Learning and Teaching, v. 11, n. 1, 2012.

GILL, R. Análise de discurso. In: BAUER, M. W; GASKELL, G. Pesquisa Qualitativa com texto, imagem e som: um manual prático. $2^{\circ}$ ed. Petrópolis: Vozes, 2003, p. 244-270.

GOMES, R. A análise e interpretação de dados de pesquisa qualitativa. In: MINAYO, M. C. de S. (Org.). Pesquisa social: teoria, método e criatividade. Rio de Janeiro: Vozes, 2013, p. 79-108.

GOMES, B.; BRIDI, C.; LARA, M. Radicalismo político no Brasil supera média de 27 países. Jornal Estadão, 14 abr. 2019. Disponível em: <https://politica.estadao.com.br/noticias/geral,radicalismo-politico-no-brasilsupera-media-global,70002790753>. Acesso em 14 abr. 2019.

GONÇAlVES, M. A.; ALVARENGA FILHO, J. R.; CUNHA, C. C.; PORTUGAL, F. T (Orgs.). Psicologia, Direitos Humanos e Movimentos Sociais: Capturas e insurgências na cidade. Florianópolis: Abrapso, 2017. Disponível em: <https://www.abrapso.org.br/download/download?ID_DOWNLOAD=551>. Acesso em 18 abr. 2019.

GONZÁLEZ-REY, L. F. Pesquisa qualitativa em Psicologia: caminhos e desafios. São Paulo: Cengage Learning, 2011.

GUBA, E. G.; LINCOLN, Y. S. Competing paradigms in qualitative research. In: DENZIN, N. K.; LINCOLN, Y. S. (Orgs.), Handbook of qualitative research. Califórnia: Sage, 1994, p. 105-117.

IGNÁCIO, P. S.; CAVOUR, F. S. Os caminhos da restituição: a afirmação de outros modos de fazer pesquisa e de se fazer pesquisador. In: NASCIMENTO, M.L.; AYRES, L.; COIMBRA, C. M. B.. (Orgs.). Pivetes: Encontros entre a psicologia e o judiciário. Curitiba: Juruá, v. 1, 2008, p. 70-76.

SBPC - SOCIEDADE BRASILEIRA PARA O PROGRESSO DA CIÊNCIA. Corte orçamentário atinge desenvolvimento e soberania nacionais. Jornal da Ciência, 4, 2019. Disponível em: <http://jcnoticias.jornaldaciencia.org.br/wp-content/uploads/2019/04/Of.-SBPC-035-manifestoconjunto_corte-or\%C3\%A7ament\%C3\%A1rio-2019.pdf>. Acesso em 21 abr. 2019.

KIND, L. Notas para o trabalho com a técnica de grupos focais. Psicologia em Revista, v. 10, n. 15, p. 124136, jun. 2004. Disponível em: <http://periodicos.pucminas.br/index.php/psicologiaemrevista/article/ view/202/213>. Acesso em 18 abr. 2019.

LOIZOS, P. Vídeo, filme e fotografias como documentos de pesquisa. In: BAUER, M. W.; GASKELL, G. Pesquisa Qualitativa com texto, imagem e som: um manual prático. $2^{\circ}$ ed, Petrópolis: Vozes, 2003, p. 137-155.

MACHAMER, P.A Brief Historical Introduction to the Philosophy of Science. In: MACHAMER, P.; SILBERSTEIN, M. (Eds.). The Blackwell Guide to the Philosophy of Science. Malden: Blackwell Publishers. 2002.

MAIA, A. F. Psicologia, política e direitos humanos: ambiguidades e contradições. Revista Interdisciplinar de Direitos Humanos, v.2, n.2, p. 131-144, 2014. Disponível em: <https://www3.faac.unesp.br/ridh/index.php/ridh/article/view/180>. Acesso em 18 abr. 2019.

MARTINS, H. H. T. de S. Metodologia qualitativa de pesquisa. Educação e pesquisa, v. 30, n. 2, p. 289-300, maio/ago, 2004. Disponível em: <http://www.scielo.br/pdf/ep/v30n2/v30n2a07.pdf〉. Acesso em 18 abr. 2019.

MATOS-SILVA, M. S. de. Compartilhando vidas on-line: a pesquisa biográfica por meio da internet. In: NICOLACI-DA-COSTA, A. M.; ROMÃO-DIAS, D. (Orgs.). Qualidade faz diferença: métodos qualitativos de pesquisa para psicologia e áreas afins. Rio de Janeiro e São Paulo: Ed PUC-Rio e Edições Loyola, 2013, p. 199-224. 
MAY, T. (2004). Capítulo 7: Observação Participante: perspectivas e prática. In: MAY, T. (2004). Pesquisa Social: questões, métodos e processos. $3^{\mathrm{a}}$ ed. Porto Alegre: Artmed, p. 173-203.

MINAYO, M. C. de S.; SANCHES, O. Quantitativo-qualitativo: oposição ou complementaridade. Rio de Janeiro: Cadernos de saúde pública, v. 9, n. 3, p. 239-262, 1993. Disponível em: <http://www.scielo.br/pdf/csp/v9n3/02.pdf>. Acesso em 18 abr. 2019.

MIZRAHI, M. Indumentária funk: a confrontação da alteridade colocando em diálogo o local e o cosmopolita. Horiz. Antropol., v. 13, n. 28, p. 231-262, dez. 2007. Disponível em: <http://www.scielo.br/scielo.php? script=sci_arttext\&pid=S0104-71832007000200010\&lng=en\&nrm=iso>. Acesso em 17 jan. 2018.

MOREIRA, I. C. Situação muito grave da ciência e tecnologia no Brasil. 2017. Disponível em $<$ https://www2.camara.leg.br/atividade-legislativa/comissoes/comissoes-permanentes/cctci/audienciaspublicas/2017/2017-10-10-ap-o-orcamento-da-ciencia-e-tecnologia-seus-cortes-e-consequencias/ildeumoreira-sbpc>. Acesso em 21 abr. 2019.

NEVES, V. F. A. Pesquisa-ação e Etnografia: Caminhos Cruzados. Pesquisas e Práticas Psicossociais, v. 1, n. 1, p. 1-17, jun. 2006. Disponível em: <https://ufsj.edu.br/portal-repositorio/File/revistalapip/PesquisaAcao_e_Etnografia..._-_VFA_Neves.pdf>. Acesso em 18 abr. 2019.

NOVO, H. A. Fazer ciência na torre de Babel: conversando com alunos de psicologia. In: MENANDRO, Z. A. T. (Org.) Pesquisa em Psicologia: recriando métodos. Vitória: UFES, 1999, p. 61-72.

PERES, R. S.; SANTOS, M. A. dos. Considerações gerais e orientações práticas acerca do emprego de estudos de caso na pesquisa científica em psicologia. Interações, v. 10, n. 20, p. 109-126, 2005. Disponível em: <http://pepsic.bvsalud.org/scielo.php?script=sci_arttext\&pid=S1413-29072005000200008>. Acesso em 18 abr. 2019.

PILLA, A.; QUADROS, C. M. B. de. Charge: Uma leitura orientada pela análise do discurso da linha francesa. Linguagens: Revista de Letras, Artes e Comunicação (FURB), v. 3, p. 226-239, 2009. Disponível em: <http://proxy.furb.br/ojs/index.php/linguagens/article/view/1497/1402>. Acesso em 17 jan. 2018.

PORTAL DA TRANSPARÊNCIA. Conselho Nacional de Desenvolvimento Científico e Tecnológico. CNPQ. Disponível em: <http://www.portaltransparencia.gov.br/orgaos/20501?ano=2018>. Acesso em 21 abr. 2019.

QUEIROZ, M. I. P. de. Relatos orais: do "indizível" ao "dizível". In: VON SIMSON, O. M. Experimentos com histórias de vida: Itália-Brasil. São Paulo: Vértice, 1988, p.14-35.

RIZZINI, I.; CASTRO, M. R. de; SARTOR, C. D. A Pesquisa Participativa. In: RIZZINI, I.; CASTRO, M. R. de; SARTOR, C. D. Pesquisando... Guia de metodologias de pesquisa para programas sociais. Rio de Janeiro: USU, 1999, p. 37-51.

RODRIGUES, R. O.; CRUZ, S. G. F. P. Interlocuções entre Psicologia e Direitos Humanos: práticas interventoras. R. Ci. Hum. Universidade Federal de Santa Catarina, v. 47, n. 2, 2013. Disponível em: <https://periodicos.ufsc.br/index.php/revistacfh/article/view/2178-4582.2013v47n2p198>. Acesso em 18 abr. 2019.

ROMÃO-DIAS, D. Os métodos qualitativos e a psicologia: uma história feita de estórias. In: NICOLACI-DACOSTA, A. M.; ROMÃO-DIAS, D. (Orgs.). Qualidade faz diferença: métodos qualitativos de pesquisa para psicologia e áreas afins. Rio de Janeiro e São Paulo: Ed PUC-Rio e Edições Loyola, 2013, p. 17-39.

ROSATO, C. M. Psicologia e Direitos Humanos: cursos e percursos comuns. Psic. Rev. São Paulo, v. 20, n.1, 11-27, 2011. Disponível em: <http://revistas.pucsp.br/psicorevista/article/view/6790/4913>. Acesso em 18 abr. 2019.

SANTOS, B. S. A Universidade do Século XXI: Para uma Reforma Democrática e Emancipatória da Universidade. 3 ed. São Paulo: Cortez, 2011.

SANTOS, L. A. de C.; JEOLÁS, L. Uma comissão nacional de ética em pesquisa, as ciências biomédicas e as ciências humanas: trespassing à brasileira. Revista brasileira de sociologia, v. 03, n. 05, 2015. Disponível 
em: <http://www.sbsociologia.com.br/revista/index.php/RBS/article/view/102/76>. Acesso em 17 jan. 2018.

SCHWEDE, G.; BARBOSA, N. H.; SCHRUBER-JUNIOR, J. Psicologia nos direitos humanos: possibilidades de mediações semióticas. Psicol. Soc. [online], v.20, n.2, p. 306-312, 2008. Disponível em: <http://www. scielo.br/scielo.php?script=sci_arttext\&pid=S0102-71822008000200018\&lng=en\&nrm=iso $>$. Acesso em 18 abr. 2019.

TAVARES, G. M.; FRANCISCO, R. S. Pesquisa como acontecimento: exercícios de escreverCOM. Rev. Polis e Psique, v. 6, n. 1, p. 136-148, 2016. Disponível em: <http://seer.ufrgs.br/index.php/PolisePsique/article/ view/61388>. Acesso em 17 jan. 2018.

UNIVERSIDADE FEDERAL DE MINAS GERAIS. Matriz Curricular: Versão 2009/1. 2009a. Disponível em: <https://www2.ufmg.br/psicologia/content/download/3588/30113/file/MATRIZ\%20CURRICULAR \%20-\%202009>. Acesso em 17 jan. 2018.

Matriz Curricular 2009/1: Ementas. 2009b. Disponível em: <https://colgrad.ufmg.br/psicologia/ content/download/22298/152796/file/EMENTAS\%20-\%20MATRIZ\%202009-1.pdf>. Acesso em 17 jan. 2018.

VALLADARES, L. Os dez mandamentos da observação participante. Rev. Bras. Ci. Soc., v. 22, n. 63, p. 153155, 2007. Disponível em: <http://www.scielo.br/scielo.php?script=sci_arttext\&pid=S010269092007000100012\&lng=en\&nrm=iso>. Acesso em 17 jan. 2018.

WILLIG, C.; STAINTON-ROGERS, W. The SAGE handbook of qualitative research in psychology. Los Angeles, SAGE: 2008.

\section{Correspondência}

Laura Cristina Eiras Coelho Soares: Docente do Departamento de Psicologia e do Programa de PósGraduação em Psicologia da Universidade Federal de Minas Gerais - UFMG. Doutora e Mestre em Psicologia Social pela Universidade do Estado do Rio de Janeiro - UERJ.

E-mail: laurasoarespsi@yahoo.com.br

ORCID: 0000-0003-0859-7625

Ariane Agnes Corradi: Docente do Departamento de Psicologia e do Programa de Doutorado Acadêmico em Inovação Tecnológica da Universidade Federal de Minas Gerais - UFMG. Doutora em Estudos do Desenvolvimento pelo International Institute of Social Studies da Universidade Erasmus de Roterdã e Mestre em Psicologia pela Universidade de Brasília - UNB.

E-mail: acorradi@ufmg.br

ORCID: 0000-0002-3023-3425

Déborah David Pereira: Aluna do curso de graduação em Psicologia da Universidade Federal de Minas Gerais - UFMG.

E-mail: deborahdavidp@gmail.com

ORCID: 0000-0001-5144-6430

Texto publicado em Currículo sem Fronteiras com autorização das autoras 